\title{
Reporter Dimension
}

National Cancer Institute

\section{Source}

National Cancer Institute. Reporter Dimension. NCI Thesaurus. Code C44262.

Specialized DesignElementDimension to hold Reporters. 